\title{
The effect of virtual reality technology on preoperative anxiety in children: a Solomon four-group randomized clinical trial
}

\author{
Fateme Dehghan ${ }^{1,2}$, Rostam Jalali $^{3^{*}}$ (D) and Hasan Bashiri ${ }^{1}$
}

\begin{abstract}
Background: Preoperative anxiety correlates positively with the amount of postoperative pain, analgesic use, and length of hospital stay. The purpose of this study was to investigate the effect of virtual reality technology on pre-operative anxiety in children.

Methods: The study utilized Solomon four-group design intervention and a randomized clinical trial. A total of 40 candidates undergoing abdominal surgery were randomly divided into two groups. The pre-operative anxiety scale was assessed by a checklist containing a standardized Yale Preoperative Anxiety Scale questionnaire. The interventional group had a 5-min exposure to the operating room using virtual reality technology, but the control group did not receive virtual reality exposure. The data were analyzed using SPSS-23 software.

Results: Non-parametric test for two independent groups showed no significant difference in baseline scores between interventional 1 and control 1 groups except for vocalization $(p=0.019)$, but there was a significant change in all subscales among intervention group 1 from baseline to post-test $(p<0.05)$ except for state of apparent arousal.

Conclusions: The medical treatment using virtual reality technology, as well as distraction and drowning in the virtual reality, reduced pre-operative anxiety in children.
\end{abstract}

Keywords: Preoperative anxiety, Virtual reality, Children, Medical exposure

\section{Background}

Preoperative anxiety is a natural and compatible response to surgery stress which may happen at any time before surgery (Bahrami et al. 2012). This stress is intensified when a patient is informed about the need for surgery, at the initiation of surgery, and during hospitalization (Matthias and Samarasekera 2012; Nourian et al. 2014). Some signs of stress include anxiety, distraction, irritation, fear, and increase in heart rate (Perry et al. 2012). Preoperative anxiety is a potential threat for a patient due to the changes in psychologic responses, including elevation of blood pressure and heart rate, and may endanger patient's health (Namazi et al. 2014).

Patient anxiety may increase complications of surgery and anesthesia. Preoperative anxiety can reduce the quality

\footnotetext{
*Correspondence: Ks_jalali@yahoo.com

${ }^{3}$ Nursing Department, Faculty of Nursing and Midwifery, Kermanshah

University of Medical Sciences, Isar Square, Kermanshah, Iran

Full list of author information is available at the end of the article
}

of anesthesia and increase demand for analgesics, which can inadvertently prolong the duration of anesthesia. The patient wakes up from anesthesia later, which leads to increase anesthesia and surgery complications. Moreover, anxiety is accompanied by psychologic responses including high blood pressure and cardiac arrhythmia. Generally, there are degrees of preoperative anxiety in all patients, but it is higher in children and requires special attention (Jenkins et al. 2014; Williams and Jones 1968; McCleane and Cooper 1990; Goldman et al. 1988; Jlala et al. 2010). Children, particularly in the early years of their life, are vulnerable to this matter because stress alters the usual pattern of health as well as the safe and familiar environment for the child. On the other hand, children have limited coping mechanisms for resolving stressful situations (Hockenberry and Wilson 2014). Anxiety during hospitalization depends on the evolutionary level of children, history of separation from parents or hospitalization, and an accessible supportive system. Although school children can better accept

(c) The Author(s). 2019 Open Access This article is distributed under the terms of the Creative Commons Attribution 4.0 International License (http://creativecommons.org/licenses/by/4.0/), which permits unrestricted use, distribution, and 
separation, separation anxiety during hospitalization may increase their need for security and parents. The worst stressful factors in school children during hospitalization are exposure to strange individuals, unfamiliar nutrition pattern, and separation from family, unfamiliar environment, treatment process, and lack of control (Uddin et al. 2002). Preoperative anxiety not only causes pain and discomfort for many children with surgery experience, but also has a negative impact on post-surgical duration of improvement and recovery (Ahmed et al. 2011). Postoperative anxiety behaviors are negative behaviors during surgery experience, including impatience, crying, unintentional urination, and need to physical limiting tools during anesthesia (Wright et al. 2007), and are accompanied by some other postoperative inconsistent behaviors, including distress addition in recovery level, return behavioral disorders after the surgery (nightmare), separation anxiety, eating disorder, and sleep and enuresis disorders (Babashahi et al. 2010).

In fact, some benefits including reducing anxiety are better recovery, quick improvement, reduction of drugs for anesthesia, better pain tolerance, and reduction in hospital stay, which lead to the reduction of costs and complications after the surgery (Babashahi et al. 2010). Anxiety, particularly in children, may cause undesirable mental complications in the future (Bagherian et al. 2012). Anxiety reduction can be performed using two methods including pharmacological and non-pharmacological methods. A non-pharmacological way of reducing anxiety is individual confrontation (Hasani et al. 2009). In recent years, advancements in information and communication technology have led to more effective psychological interventions. Virtual reality and telepsychology are two technologies that are applied in clinical psychology (Botella et al. 2009). Virtual reality can be a potential method for providing public and private healthcare services. It seems that virtual reality can enter psychotherapy process. A panel consisted of 62 psychotherapy specialists tried to respond to the question what is the future of psychotherapy? According to their responses, the usage of only 18 therapeutic interventions out of 38 psychotherapy methods was predicted to increase in the future decade. In this ranking, virtual reality was in the third place (Riva 2005).

North and North observed a feeling of fear in some participants during a military navigation software test. Accordingly, they concluded that this technology not only leads to fear but also can be used for coping with fear and other mental disorders. They introduced virtual reality exposure therapy (VRET) as a new therapeutic method that enables patient exposure to the problems and help them cope with their irrational behaviors. The key issue is that participants, by entering the virtual world, know that there is no danger while they see fearful images similar to real life. This exposure provides a feeling of fear and results in coping (North and North 2016).
The most common application of virtual reality in clinical psychology is in the treatment of phobias. In fact, VRET is introduced as a new tool for therapeutic exposure which is safer, less embarrassing, and cost-effective in comparison with real situations (Rothbaum 2010). The logic behind VRET is simple; patient encounters with deliberate fearful drivers while there is the possibility of reducing patient's anxiety. Avoiding fearful situations that lead to continuity of fear including situations with frequent encounters (blood sampling and dental extraction procedures) also lead to removing fear (Riva 2005). The VRET is similar to real-world treatment since it causes patients to feel the exposure to motivating drivers of fear. The difference between VRET and traditional behavioral therapy is that graphic image technology, monitors, and input tools simulate an environment the same as real life in laboratory environment. Consequently, VRET provides the feeling of existence for participants with immersion feeling in fearful scene (Riva 2003).

The VRET has advantages over real or imaginary encounter. Firstly, VRET can be executed in usual psychotherapy environments like clinics. Secondly, fearful attributes of a patient can be more effectively separated in comparison with traditional methods (for example, fear for landing in an individual with fear of flying can be repeated in VRET frequently without waiting for a real flight). Thirdly, the immersive nature of VRET can provide a more real experience for motivating emotions than imaginary encounter. Fourthly, this mode can provide effective extinction in fear responses (Riva 2003). Finally, VRET can depict fearful situations with higher intensity than real treatment. Therefore, in cases that real encounter is difficult, VRET can be an alternate for medicinal choices (North and North 2016). Furthermore, patients' acceptance of virtual reality is high. In the study by Garcia-Palacios et al., the number of sessions of real encounter was compared to VRET. They found that approximately $80 \%$ of subjects preferred VRET to real encounter (North and North 2016).

Studies show that patients who use reducing methods for anxiety or compatibility skills before surgery have less anxiety and report lower physical pain after surgery. Furthermore, duration of hospitalization after surgery and patients' demand for painkillers are reduced in cases who had less preoperative anxiety (Durling et al. 2007). However, there were a few researches which measure the effect of VRET on preoperative anxiety in children. Therefore, the present research considers the effect of VRET on preoperative anxiety in children.

\section{Methods}

The present research was a Solomon four-group interventional study (two experimental groups and two control groups) in randomized controlled trial design. This 
design is used to remove extraneous effect of pretest on the result of study especially in children.

The participants were children undergoing surgery and gave a written informed consent from legal administrator. Sampling method was convenience (non-random), but allocations to groups were performed randomly by assigning patients with even hospital bed numbers in the interventional group and those with odd hospital bed numbers in the control group. The criteria for inclusion criteria were age between 6 and 12 years old, being a candidate for abdominal surgery, lack of previous history for abdominal surgery, and lack of mental disease, which was performed through studying patient's medical documents or asking question from their parents/guardians. The exclusion criteria were having stress or special problems in using eyeglass or headphone in VRET. The data collection tool was standardized Yale Preoperative Anxiety Scale questionnaire (Tou et al. 2013). This questionnaire has four domains including activity, vocalization, emotional expressivity, and state of apparent arousal.

Each domain has 4 items that are scored from 1 to 4 , which sum to the minimum score of 4 and maximum score of 16 .

The sample size was calculated based on the findings of a previous study (Chimeremeze et al. 2013) considering $\alpha=5 \%$ and $\beta=0 / 2$ using the following equation:

$$
N=(1.96+1.28)^{2}(16.3+17.3)^{2} /(59.1-31.5)^{2}=8
$$

According to possible sample attrition, the sample size in each group was increased by $20 \%$, which resulted in the addition of 10 patients in each group. The total sample size was therefore 40 children.

After selecting study samples, participants were divided into two interventional groups and two control groups randomly and the pretest was executed in two groups (interventional 1 and control 1) out of four groups. Subjects in the interventional group encountered the situation through virtual reality by applying eyeglass, which provided a wide field of vision and also provided proper vision for the patient. The patient was placed in front of a computer monitor to present the simulated steps of going to operation room. A headphone was placed on the patient's ears, and the simulated sounds of entrance to virtual environment were played through the headphones. The intervention was programmed in a way that the virtual drivers could be observed and heard by participants and they were immersed in the virtual environment by involving visual and auditory senses. However, the parents of patients in the control group were requested to touch and caress their children prior to operation. Pretest was performed for one of the interventional and one of the control groups while all groups filled the post-test questionnaire (Fig. 1). The Statistical Package for Social Sciences (SPSS) software version 23 was used for data analysis.

\section{Results}

The study patients included 9 girls (22/5\%) and 31 boys (77/5\%) with the age of $7 / 35 \pm 2 / 05$ years. Assessment of the normal distribution of data was performed using the Kolmogorov-Smirnov test, which was significant for posttest scores $(p<0 / 05)$. Therefore, nonparametric tests were used for analysis (Table 1). The Mann-Whitney test showed no statistical difference between groups except for the vocalization domain in pretest (Table 2). For comparing the effect of the intervention, the Kruskal-Wallis (nonparametric test) was used instead of the analysis of variance (ANOVA) and the comparison between groups was performed using the Mann-Whitney test (Table 3).

The comparison of pre- and post-scores in the interventional groups by Wilcoxon test indicated a significant statistical difference in all domains except for arousals domain. Comparison of pre- and post-scores among control groups showed a significant statistical difference in all domains except for emotional expressivity (Table 4)

\section{Discussion and conclusion}

The results of this study showed that children in the interventional groups with pretest-posttests and control groups with posttest had a significant reduction in the preoperative anxiety score after therapeutic exposure using VRET while no significant change in anxiety score of children was observed in the control group. The considerable attraction ability of VRET in distraction from the real world allows the patient to tolerate preoperative anxiety. This finding supports the idea of performing studies to develop distraction techniques. Furthermore, the findings of this study confirm the effect of VRET on unfamiliar and stressful situation exposure like operation room. These findings were in accords with the findings of the studies by Eslami et al. 2015, Afsharian 2016, Memarzadeh et al. 2006, Majzoobi et al. 2013, Robertson et al. 2017, and Shahid et al. 2015.

As it is said, the effects of preoperative anxiety on children are different from postoperative anxiety and are particularly affected by the underlying disease and postoperative improvement, but most individuals believe that preoperative anxiety is determined by private feelings including pressure, impatience, anxiety, and disappointment. In addition, preoperative anxiety, at slight and moderate levels, leads to behavioral improvement after surgery (Nourian et al. 2014), but high preoperative anxiety leads to undesirable psychological and mental consequences (Perry et al. 2012; Namazi et al. 2014; Jenkins et al. 2014). 


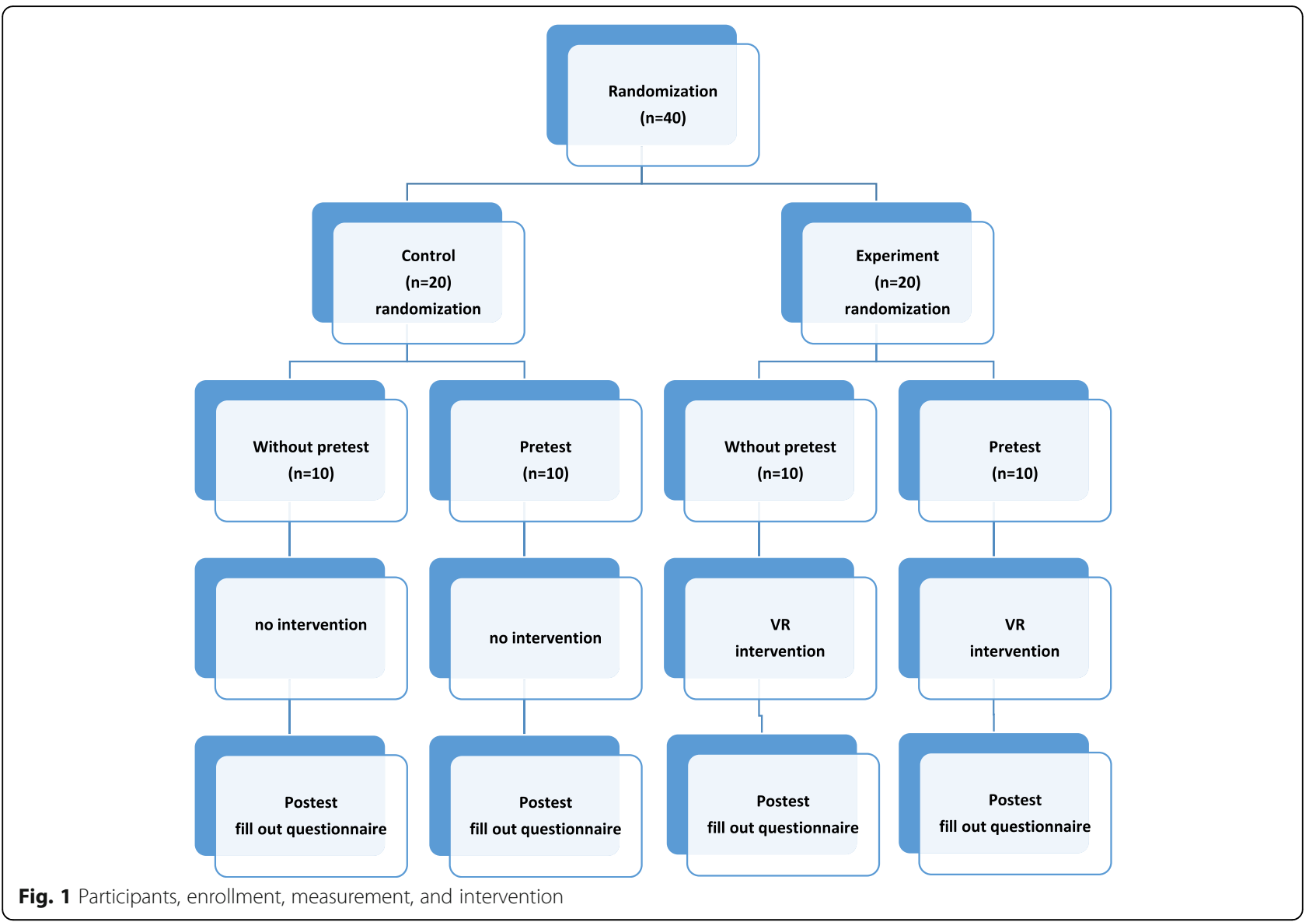

In children, preoperative anxiety may lead to high mental pressure and negative mental effects, which are accompanied by nightmares and impatience during sleep, separation anxiety, nutritional and growth problems, and fear of medical personnel (Namazi et al. 2014; Jenkins et al. 2014).

These positive results for immersing in VRET support the hypothesis that this media can banish maximum attention from real world and then, allows patients to tolerate preoperative anxiety (Hoffman et al. 2014). In a study, application of VRET reduced preoperative anxiety in children by 30\% (Ryu et al. 2017). During cognitivebehavioral treatment for anxiety disorder, patients who were affected by real-life problems and/or through virtual reality in anxiety conditions were compared. Their experience indicated that feeling of presence had a positive relationship with anxiety level. Furthermore, there was a considerable additional effect in stress response, including elevation of serum cortisol level, saliva, and cardiovascular responses, in both real and VRET groups, which indicates the usefulness of VRET programs for the treatment of anxiety (Ling et al. 2014; Kothgassner et al. 2016).

Table 1 One-sample Kolmogorov-Smirnov test

\begin{tabular}{|c|c|c|c|c|c|}
\hline & & Activity post & Vocalization post & Emotional expressivity post & State of apparent arousal post \\
\hline N & & 40 & 40 & 40 & 40 \\
\hline \multirow[t]{2}{*}{ Normal Parameters ${ }^{\mathrm{a}}$} & Mean & 1.90 & 2.40 & 2.22 & 1.68 \\
\hline & Std. deviation & 1.236 & 1.499 & 1 & 1.095 \\
\hline \multirow[t]{3}{*}{ Most extreme differences } & Absolute & 0.342 & 0.305 & 0.256 & 0.406 \\
\hline & Positive & 0.342 & 0.305 & 0.215 & 0.406 \\
\hline & Negative & -0.233 & -0.175 & -0.256 & -0.269 \\
\hline Kolmogorov-Smirnov Z & & 2.161 & 1.930 & 1.618 & 2.569 \\
\hline Asymp. Sig. (2-tailed) & & 0.000 & 0.001 & 0.011 & 0.000 \\
\hline
\end{tabular}

\footnotetext{
${ }^{a}$ Test distribution is normal
} 
Table 2 The comparison of post-intervention scores between four groups

\begin{tabular}{|c|c|c|c|}
\hline Domains & Groups & Mann-Whitney & Kruskal-Wallis \\
\hline \multirow[t]{5}{*}{ Activity after } & \multirow[t]{3}{*}{ E1 } & $\mathrm{E} 2 p=0.436$ & \multirow[t]{5}{*}{$p=0.005$} \\
\hline & & $C 1 p=0.105$ & \\
\hline & & $C 2 p=0.003$ & \\
\hline & \multirow[t]{2}{*}{ E2 } & $C 1 p=0.393$ & \\
\hline & & $C 2 p=0.023$ & \\
\hline \multirow[t]{5}{*}{ Vocalization after } & \multirow[t]{3}{*}{ E1 } & $E 2 p=0.529$ & \multirow[t]{5}{*}{$p=0.003$} \\
\hline & & $C 1 p=0.011$ & \\
\hline & & $C 2 p=0.004$ & \\
\hline & \multirow[t]{2}{*}{ E2 } & $C 1 p=0.105$ & \\
\hline & & $C 2 p=0.015$ & \\
\hline \multirow[t]{5}{*}{ Emotional expressivity after } & \multirow[t]{3}{*}{ E1 } & $\mathrm{E} 2 p=0.436$ & \multirow[t]{5}{*}{$p=0.001$} \\
\hline & & $C 1 p=0.001$ & \\
\hline & & $C 2 p=0.001$ & \\
\hline & \multirow[t]{2}{*}{ E2 } & $C 1 p=0.035$ & \\
\hline & & $C 2 p=0.023$ & \\
\hline \multirow[t]{5}{*}{ State of apparent arousal after } & \multirow[t]{3}{*}{ E1 } & $E 2 p=0.739$ & \multirow[t]{5}{*}{$p=0.000$} \\
\hline & & $C 1 p=0.143$ & \\
\hline & & $C 2 p=0.002$ & \\
\hline & \multirow[t]{2}{*}{ E2 } & $\mathrm{C} 1 p=0.218$ & \\
\hline & & $C 2 p=0.003$ & \\
\hline
\end{tabular}

E1 experiment 1 (intervention with pretest), E2 experiment 2 (intervention without pretest), C1 control 1 (control with pretest), C2 control 2 (control without pretest)

Therefore, exposure to VR can be operational and alternative for traditional methods of reducing anxiety because it has further control on anxiety level of the simulator. Children with virtual reality experience have further compatibility during rapid anesthesia than those who received traditional instructions. Children who experienced VRET may be more familiar with the operation room environment and preoperative process than those who experienced usual instruction (Ryu et al. 2018).

Recent studies showed that preoperative expectation can be improved through experience of the new technologies. Furthermore, VRET can be applied for other stressful conditions or similar critical effective factors. Therefore, the findings of the new exciting studies suggest the

Table 3 The comparison of pre-intervention scores between two groups

\begin{tabular}{llll}
\hline Domains & \multicolumn{2}{l}{ Mann-Whitney } & Sig \\
\hline Activity before & E1 & C1 & $p=0.143$ \\
Vocalization before & E1 & C1 & $p=0.019$ \\
Emotional expressivity before & E1 & C1 & $p=0.393$ \\
State of apparent arousal before & E1 & C1 & $p=0.912$ \\
\hline
\end{tabular}

E1 experiment 1 (intervention with pretest), $C 1$ control 1 (control with pretest) performance of further researches in this field. Generally, recent studies used functional magnetic resonance imaging (FMRI), which is a neural imaging process which uses MRI technology for the evaluation of brain performance through certain changes in blood flow, suggesting that VRET may reduce psychological responses to a stressful stimulator (pain). Furthermore, mental advantage may explain the reduced mental responses for guiding conscious attention in a recent study. Both heart rate and blood pressure are dynamic attributes that can be generally altered due to response to physical and emotional stimulators. These evaluations are registered concisely in a situation like patient's movement or exposure to medical personnel (De Queiroz Siqueira et al. 2016).

According to items in movie $\left(360^{\circ}\right)$, the early data of entering the operation room experience for children by application of eyeglass and virtual reality headphone and expectation based on reality lead to cognitive control, which reduces destructive effects of stress (Auerbach et al. 1983). Particularly, the presentation of data in movie format reduces children's preoperative anxiety and accelerates recovery (Nourian et al. 2014; Tou et al. 2013). Children who find further mental preparation present less signs of emotional disturbance (Afsharian 2016). The observed results can be explained in some psychological theories.

Since children in the interventional group expressed lower anxiety in comparison with the control group, it can be said that VRET to hospital environment, including ward and operation room, provides mental preparation for children and realistic expectation, which are formed in their minds that cause cognitive control, and consequently, the destructive effects of imminent stress are reduced (Jenkins et al. 2014). Moreover, virtual encounter increases the ability for predicting future situations. It is obvious that non-predictable events can cause different kinds of cognitive, emotional, and physical incompatible signs. On the other hand, when children are placed in a naturally painful situation (hospital and

Table 4 The comparison of pre- and post-intervention scores of each domain

\begin{tabular}{llll}
\hline Domains & Wilcoxon & & Sig \\
\hline Activity & E1b & E1a & $p=0.026$ \\
Vocalization & C1b & C1a & $p=0.334$ \\
Emotional expressivity & E1b & E1a & $p=0.007$ \\
& C1b & C1a & $p=0.054$ \\
State of apparent arousal & E1b & E1a & $p=0.015$ \\
& C1b & C1a & $p=0.023$ \\
& E1b & E1a & $p=0.063$ \\
& C1b & C1a & $p=1$ \\
\hline
\end{tabular}

E1 experiment 1 (intervention with pretest), C1 control 1 (control with pretest), $b$ before, $a$ after 
expectation for surgery), the probability of anxiety is increased intensely. Prediction ability is an intrinsically desirable matter that can increase the chance for compatibility to stressful factors in children. Therefore, mental processes and sequence, which increase patient's capacity for predicting stressful events, are desirable and provide the means for improving the compatibility behaviors in children (Memarzadeh et al. 2006).

In cognitive domain, the probability of cooperation is increased when a child watches the movie of his contemporary child, and it is determined for him that his contemporary child also experienced all exposure levels, and he is assured that there is no threat for him in the operation room (Robertson et al. 2017). Considering the improved accessibility to economical devices, the VRET hardware has the potential for widespread use in the society than before (Parsons et al. 2017).

The limitations of this research include lack of consideration of physiological signs of children before surgery (blood pressure and pulse rate), lack of homogenization of the type of surgery, and small sample size. On the other hand, according to the differences in intelligence, social class, level of parental attachment in children, and anxiety of parents, the findings of this study should be cautiously generalized to all children of the same age. In the control group, children received only usual instructions. Statistically, although ANOVA must be used for comparison of groups, due to the non-normally distribution of the data, the alternative non-parametric tests were used.

This study indicated the effectiveness of distraction and immersion in virtual reality for the purpose of encounter exposure on preoperative anxiety in children. Using virtual reality and reducing attention to environment and distraction allow patients to tolerate preoperative anxiety. The VRET virtually exposes the patient to stressful and unfamiliar situations in a safer environment before the real encounter. This technique results in the sensation of familiarity in the real encounter in the patient and thus result in reduced anxiety.

\section{Abbreviations}

ANOVA: Analysis of variance; C1: Control 1; C2: Control 2; E1: Experiment 1; E2: Experiment 2; IRCT: Iranian Registry of Clinical Trial; KUMS: Kermanshah University of Medical Sciences; VR: Virtual reality; VRET: Virtual reality exposure therapy; VRET: Virtual reality exposure therapy

\section{Acknowledgements}

This paper reports the results of a research project sponsored by the Kermanshah University of Medical Sciences (grant no: 96056).

\section{Authors' contributions}

$\mathrm{R} J$ contributed to the design, analysis, and most of the study steps. FD prepared the manuscript. $\mathrm{HB}$ assisted in designing the study and helped in the interpretation of the study findings. All authors have read and approved the content of the manuscript.

\section{Funding}

This study was funded by the Kermanshah University of Medical Sciences (grant number: 96056).

\section{Availability of data and materials}

Datasets can be accessed through the corresponding author upon reasonable request.

\section{Ethics approval and consent to participate}

Informed consent was obtained from all participants in the study. This study was conducted by the Kermanshah University of Medical Sciences (research number 96056). This research was approved by the Ethical Committee of Kermanshah University of Medical Sciences (code: KUMS.REC.1395.659). The research is also registered in the Iranian Registry of Clinical Trials (code: IRCT2017021525433N3).

\section{Consent for publication}

Not applicable.

\section{Competing interests}

The authors declare that they have no competing interest.

\section{Author details}

${ }^{1}$ Kermanshah University of Medical Sciences, Kermanshah, Iran. ${ }^{2}$ Department of Psychology, Faculty of Social Sciences, Razi University, Kermanshah, Iran.

${ }^{3}$ Nursing Department, Faculty of Nursing and Midwifery, Kermanshah

University of Medical Sciences, Isar Square, Kermanshah, Iran.

Received: 3 March 2019 Accepted: 13 May 2019

Published online: 04 June 2019

\section{References}

Afsharian N. A survey of effectiveness of virtual reality exposure therapy in reducing the driving phobia: a case study. Psychological Studies Faculty of Education and Psychology Alzahra Univ. 2016;12(1):65-84.

Ahmed Ml, Farrell MA, Parrish K, Karla A. Preoperative anxiety in children risk factors and non-pharmacological management. Middle East J Anesthesiol. 2011;21(2):153-64.

Auerbach SM, Martelli MF, Mercuri LG. Anxiety, information, interpersonal impacts, and adjustment to a stressful health care situation. J Pers Soc Psychol. 1983;44(6):1284.

Babashahi M, Fayazi S, Aghel N, Haghighizadeh M. Effect of aromatherapy on anxiety level among preoperative patients. Jundishapur Sci Med J. 2010;9(5): $507-16$.

Bagherian S, Borhani F, Zadeh AA, Ranjbar H, Solaimani F. The effect of distraction by bubble-making on the procedural anxiety of injection in Thalassemic school-age children in Kerman Thalasemia center. Adv Nurs Midwifery. 2012;22(76):52-9.

Bahrami N, Soleymani M, Arjinee Z, Sharifnia S, Masodi R, Shahrokhi A. Impac anxious patient care based upon the nursing process for elective surgery for women. J Nurs Iran. 2012;25(77):9-30.

Botella C, Garcia-Palacios A, Baños Rivera RM, Quero Castellano S. Cybertherapy: advantages, limitations, and ethical issues. 2009.

Chimeremeze OH, Sulaiman S, Foong O-M, editors. An exploratory study on the prospect of virtual reality's key multi-sensory elements in traditional foot reflexology. Artificial Intelligence, Modelling and Simulation (AIMS), 2013 1st International Conference on; 2013: IEEE.

De Queiroz Siqueira M, Tosseti S, Marechal C, Cogniat B, Berthilier J, Chassard D. Effect of iPad tablet on children and parental anxiety during anaesthesia. Poster presented at ANCA. 2016

Durling M, Milne D, Hutton N, Ryan S. Decreasing patient's preoperative anxiety: a literature review. Medicine. 2007:15(4):245-56.

Eslami M, Haj Mirza Alian MA, Karbasi A. Design and construction of mechatronic simulation for the treatment of phobias (fear of darkness). J Mech Eng Sci. 2015;8(2):97-106

Goldman L, Ogg TW, Levey AB. Hypnosis and day case anaesthesia: a study to reduce preoperative anaesthetic requirement. Anaesthesia. 1988;43:466-9.

Hasani V, Fathi M, Saadatniaki A. Evaluation of anti anxiety effect of rectal diazepam as a premedication with oral midazolam on children who are undergoing eye surgery. 2009.

Hockenberry MJ, Wilson D. Wong's nursing care of infants and children-E-book: Elsevier Health Sciences; 2014.

Hoffman AJ, Brintnall RA, Brown JK, von Eye A, Jones LW, Alderink G, et al. Virtual reality bringing a new reality to postthoracotomy lung cancer patients via a 
home-based exercise intervention targeting fatigue while undergoing adjuvant treatment. Cancer Nurs. 2014;37(1):23-33.

Jenkins BN, Fortier MA, Kaplan SH, Mayes LC, Kain ZN. Development of a short version of the modified Yale Preoperative Anxiety Scale. Anesth Analg. 2014;119(3):643-50.

Jlala HA, French JL, Foxall GL, Hardman JG, Bedforth NM. Effect of preoperative multimedia information on periopoerative anxiety in patients undergoing procedures under regional anaesthesia. Br J Anaesth. 2010;104:369-74.

Kothgassner OD, Felnhofer A, Hlavacs H, Beutl L, Palme R, Kryspin-Exner I, et al. Salivary cortisol and cardiovascular reactivity to a public speaking task in a virtual and real-life environment. Comput Hum Behav. 2016;62:124-35.

Ling Y, Nefs HT, Morina N, Heynderickx I, Brinkman W-P. A meta-analysis on the relationship between self-reported presence and anxiety in virtual reality exposure therapy for anxiety disorders. PLoS One. 2014;9(5):e96144.

Majzoobi M, Amani R, Majzoobi F. Effects of psychological preparation on reduction of surgery anxiety signs in children. Koomesh. 2013;14(4):466-73.

Matthias AT, Samarasekera DN. Preoperative anxiety in surgical patientsexperience of a single unit. Acta Anaesthesiol Taiwanica. 2012;50(1):3-6.

McCleane GJ, Cooper R. The nature of pre-operative anxiety. Anaesthesia. 1990;45:153-5.

Memarzadeh M, Hosseinpour M, Aflakian H. Evaluation of playing room on preoperative anxiety of 2-6 years old children in AL-Zahra hospital. Iran J Surg. 2006:14(4):10-6.

Namazi M, Akbari SAA, Mojab F, Talebi A, Majd HA, Jannesari S. Aromatherapy with citrus aurantium oil and anxiety during the first stage of labor. Iran Red Crescent Med J. 2014;16(6):e18371.

North MM, North SM. Virtual reality therapy. In: Computer-assisted and webbased innovations in psychology, special education, and health. London: Elsevier; 2016. p. 141-56.

Nourian M, Jalaledinee A, Saatchi K, Kavossi Doulanfar A. Effects of stroke massage using sesame oil on hospitalization anxiety in school-age girls. Mod Care J. 2014;10(3):210-8.

Parsons TD, Riva G, Parsons S, Mantovani F, Newbutt N, Lin L, et al. Virtual reality in pediatric psychology. Pediatrics. 2017;140(Supplement 2):S86-91.

Perry JN, Hooper VD, Masiongale J. Reduction of preoperative anxiety in pediatric surgery patients using age-appropriate teaching interventions. J Peri Anesth Nurs. 2012;27(2):69-81.

Riva G. Virtual environments in clinical psychology. Psychother Theory Res Pract Train. 2003;40(1-2):68

Riva G. Virtual reality in psychotherapy. Cyberpsychol Behav. 2005:8(3):220-30.

Robertson A, Khan R, Fick D, Robertson WB, Gunaratne DR, Yapa S, et al., editors. The effect of Virtual Reality in reducing preoperative anxiety in patients prior to arthroscopic knee surgery: a randomised controlled trial. Serious Games and Applications for Health (SeGAH), 2017 IEEE 5th International Conference on; 2017: IEEE.

Rothbaum BO. Virtual reality exposure therapy. In: The Corsini encyclopedia of psychology; 2010. p. 1-2.

Ryu J-H, Park J-W, Nahm F, Jeon Y-T, Oh A-Y, Lee H, et al. The effect of gamification through a virtual reality on preoperative anxiety in pediatric patients undergoing general anesthesia: a prospective, randomized, and controlled trial. J Clin Med. 2018;7(9):284

Ryu JH, Park SJ, Park JW, Kim JW, Yoo HJ, Kim TW, et al. Randomized clinical trial of immersive virtual reality tour of the operating theatre in children before anaesthesia. Br J Surg. 2017;104(12):1628-33.

Shahid R, Benedict C, Mishra S, Mulye M, Guo R. Using iPads for distraction to reduce pain during immunizations. Clin Pediatr. 2015;54(2):145-8.

Tou S, Tou W, Mah D, Karatassas A, Hewett P. Effect of preoperative twodimensional animation information on perioperative anxiety and knowledge retention in patients undergoing bowel surgery: a randomized pilot study. Color Dis. 2013;15(5):e256-e65.

Uddin I, Kurkuman A, Jamil T. Pre-operative anxiety in patients admitted for elective surgery in King Saud Hospital, Unaizah, Al-Qassim, Kingdom of Saudi Arabia. Pak J Med Sci. 2002;18(4):306-10.

Williams JG, Jones JR. Psychophysiological responses to anesthesia and operation. J Am Med Assoc. 1968;203:415-7.

Wright KD, Stewart SH, Finley GA, Buffett-Jerrott SE. Prevention and intervention strategies to alleviate preoperative anxiety in children: a critical review. Behav Modif. 2007:31(1):52-79.

\section{Publisher's Note}

Springer Nature remains neutral with regard to jurisdictional claims in published maps and institutional affiliations.
Ready to submit your research? Choose BMC and benefit from:

- fast, convenient online submission

- thorough peer review by experienced researchers in your field

- rapid publication on acceptance

- support for research data, including large and complex data types

- gold Open Access which fosters wider collaboration and increased citations

- maximum visibility for your research: over $100 \mathrm{M}$ website views per year

At BMC, research is always in progress.

Learn more biomedcentral.com/submissions 